\title{
Cytokine accumulation in osteitis fibrosa of renal osteodystrophy
}

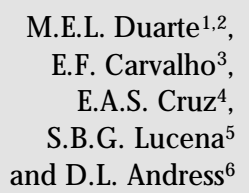

\section{Correspondence}

M.E.L. Duarte

PABCAM, UFRJ

Hospital U niversitário

Clementino Fraga Filho

Av. Brigadeiro Trompowsky, s/n

40 andar

21941-970 Rio de Janeiro, RJ

Brasil

Fax: +55-21-2610-4593

E-mail: eugenia@urbi.com.br

Received July 27, 2001

Accepted September 17, 2001

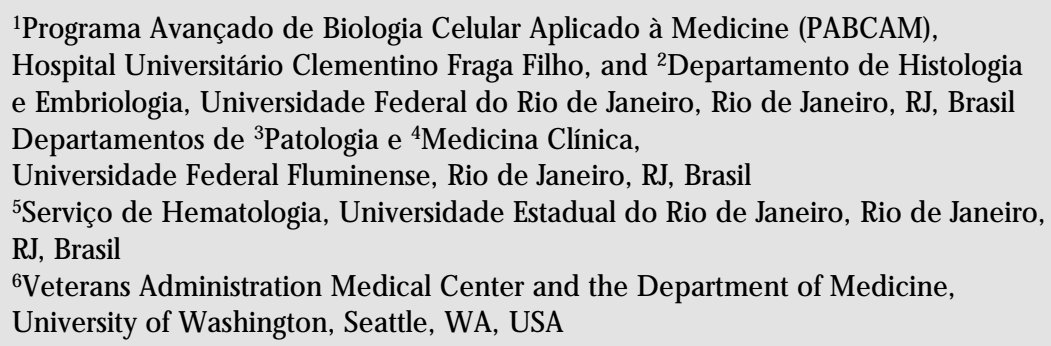

\section{Abstract}

Bone marrow fibrosis occurs in association with a number of pathological states. Despite the extensive fibrosis that sometimes characterizes renal osteodystrophy, little is known about the factors that contribute to marrow accumulation of fibrous tissue. Because circulating cytokines are elevated in uremia, possibly in response to elevated parathyroid hormone levels, we have examined bone biopsies from 21 patients with end-stage renal disease and secondary hyperparathyroidism. Bone sections were stained with antibodies to human interleukin$1 \alpha$ (IL-1 $\alpha$ ), IL-6, IL-11, tumor necrosis factor- $\alpha$ (TNF- $\alpha$ ) and transforming growth factor- $\beta$ (TGF- $\beta$ ) using an undecalcified plastic embedding method. Intense staining for IL- $1 \alpha$, IL-6, TNF- $\alpha$ and TGF- $\beta$ was evident within the fibrotic tissue of the bone marrow while minimal IL-11 was detected. The extent of cytokine deposition corresponded to the severity of fibrosis, suggesting their possible involvement in the local regulation of the fibrotic response. Because immunoreactive TGF- $\beta$ and IL- 6 were also detected in osteoblasts and osteocytes, we conclude that selective cytokine accumulation may have a role in modulating bone and marrow cell function in parathyroid-mediated uremic bone disease.

\section{Introduction}

Bone marrow fibrosis occurs in pathological states that characterize idiopathic myelofibrosis $(1,2)$ and hyperparathyroid bone disease $(3,4)$. While recent investigations have identified important constituents within fibrotic marrow in patients who have certain hematologic malignancies $(2,5-7)$, little is known about the pathogenesis of marrow fibrosis that occurs in patients with renal osteodystrophy. Specifically, questions

\section{Key words}

- Cytokines

- O steitis fibrosa

- Renal osteodystrophy

- Chronic renal failure

- Dialysis

- Secondary

hyperparathyroidism regarding fibrosis composition, its genesis and the potential role of parathyroid hormone $(\mathrm{PTH})$ in the fibrous replacement of the marrow space remain to be answered.

As seen from studies of idiopathic myelofibrosis, growth factors and cytokines are believed to promote a marrow proliferative response and the accumulation of extracellular matrix proteins (2). Whether these factors are also implicated in uremic bone disease is unknown. However, cytokines and locally derived growth factors have important roles 
in regulating normal bone metabolism $(8,9)$ and circulating levels of specific cytokines are elevated in renal failure $(10,11)$. Cytokines specifically function as translators in the mixed population of cells that reside in the bone marrow and are particularly important in modulating the bone resorptive phase of the remodeling cycle (12). Thus, the finding that PTH can stimulate selective cytokine synthesis (13) suggests that the hyperparathyroidism of renal failure may be a significant stimulus for cytokine accumulation in renal osteodystrophy.

The purpose of the present study was to determine whether specific cytokines are localized to the bone marrow stroma in dialysis patients with osteitis fibrosa.

\section{Material and Methods}

\section{Patients}

The study group consisted of 21 dialysis patients who had been previously submitted to an iliac crest bone biopsy for the investigation and treatment of high turnover bone disease. All these patients had clinical findings of bone disease such as unexplained bone and/or muscular pain and/or fractures and high (6-35-fold increase) plasma PTH levels. Written consent was obtained from all patients prior to the biopsy procedure.

\section{Bone biopsies}

The bone specimens were fixed in $70 \%$ ethanol and then dehydrated in graded ethanol prior to embedding in methyl-methacrylate (MMA). All patients were diagnosed with varying degrees of hyperparathyroidism and bone marrow fibrosis and graded as mild $(\mathrm{N}=7)$, moderate $(\mathrm{N}=7)$ and severe $(\mathrm{N}$ $=7$ ) osteitis fibrosa.

\section{Embedding}

The infiltrated specimens were embed- ded in fresh MMA, dibutyl phthalate $(3: 1)$ and $2.5 \%$ benzoyl peroxide solution at $38^{\circ} \mathrm{C}$ overnight. Five-micrometer sections were cut using a Leica RM 2155 microtome equipped with a disposable carbide steel knife. Adjacent sections were stained with Goldner trichrome (14) in order to establish the intensity of marrow fibrosis. Sections were then mounted on the slide with Haupt's gelatin and deplasticized in fresh acetone for $12 \mathrm{~h}$ at room temperature.

\section{Immunohistology}

Sections were stained using a Vectastain Elite ABC kit (Vector Laboratories, Burlingame, CA, USA) following the manufacturer's recommendations. The immunohistochemical procedure for plastic embedded bone samples has been previously described (15). Briefly, the hydrated bone sections were treated with 3\% hydrogen peroxide in $70 \%$ methanol in order to block the endogenous peroxidase. The sections were then incubated with the primary antibody for $12 \mathrm{~h}$ at $4^{\circ} \mathrm{C}$ after the blockage of nonspecific sites with $20 \%$ normal serum from the same species of the secondary antibody.

\section{Antibodies}

The following antibodies were tested: rabbit polyclonal anti-human interleukin- $1 \alpha$ (IL-1 $\alpha, 1: 400)$, anti-IL-6 (1:200), anti-tumor necrosis factor- $\alpha$ (TNF- $\alpha, 1: 500)$, and goat polyclonal anti-human IL-11 (1:200) purchased from Sigma (St. Louis, MO, USA) and a mouse monoclonal anti-human transforming growth factor- $\beta$ (TGF- $\beta, 1: 200$ ) from Chemicon (Temecula, CA, USA). The antibodies were diluted in PBS containing 1\% BSA. The primary antibody was detected by incubation with biotinylated secondary goat anti-rabbit $\operatorname{IgG}$ (1:200; Dako Corp., Carpinteria, CA, USA), whereas control sections were stained using PBS containing 1\% BSA instead of the primary antibody. Peroxidase- 
conjugated avidin-biotin complex was allowed to react with the secondary antibody and the complexes were visualized after the addition of diaminobenzidine. Sections were rinsed in distilled water and counterstained with Mayer hematoxylin.

\section{Results}

Table 1 shows the clinical and biochemical characteristics of the patients with chronic renal failure and secondary hyperparathyroidism. Bone histology was defined by histomorphometric criteria previously described (3). Hyperparathyroid bone changes were mild in 7 patients, moderate in 7 , and severe in 7 , as indicated by increased rates of bone formation and increased numbers of osteoblasts and osteoclasts lining the bone surfaces (3). Serum PTH and alkaline phosphatase were highest in the group with the most severe form of osteitis fibrosa.

Table 2 characterizes the cellular and extracellular location of immunoreactive cytokine accumulation. For all cytokines tested, except IL-11, abundant staining was present diffusely throughout most areas of fibrotic tissue. Mineralized bone and unmineralized osteoid did not stain for any of the cytokines.

Figure 1 demonstrates the relative abundance of IL- $1 \alpha$ (a), IL-6 (b), TGF- $\beta$ (c) and TNF- $\alpha$ (d) in the bone samples. Areas of non-fibrous marrow stroma were consistently negative stained for all tested cytokines (Figure 1a) and served also as internal negative control for the immunostaining procedure. Higher power micrographs showed positive osteoblast staining for IL-6 (Figure 1b) and TGF- $\beta$ (Figure 1c) but not for TNF- $\alpha$ (Figure 1d). Osteocytes also stained positive for TGFß.

While highly specific immunostaining was obtained in the fibrous marrow tissue of patients with osteitis fibrosa using each of the antisera for IL- $1 \alpha$, IL-6, IL-11, TNF- $\alpha$ and TGF- $\beta$, the removal of any one of the
Table 1. Clinical and biochemical features of patients with osteitis fibrosa.

\begin{tabular}{lccc}
\hline & \multicolumn{3}{c}{ Bone histology* } \\
\cline { 2 - 4 } & $\begin{array}{c}\text { Mild } \\
(N=7)\end{array}$ & $\begin{array}{c}\text { Moderate } \\
(N=7)\end{array}$ & $\begin{array}{c}\text { Severe } \\
(N=7)\end{array}$ \\
\hline Age & $44 \pm 6$ & $47 \pm 7$ & $46 \pm 3$ \\
Gender (M/F) & $3 / 4$ & $3 / 4$ & $3 / 4$ \\
Time on dialysis (months) & $101 \pm 16$ & $74 \pm 9$ & $115 \pm 3$ \\
Serum & $9 \pm 0.4$ & $9 \pm 0.5$ & $9.5 \pm 0.5$ \\
Calcium (mg\%) & $465 \pm 103$ & $1107 \pm 63$ & $2510 \pm 335$ \\
PTH (pg/ml) & $659 \pm 100$ & $2399 \pm 361$ \\
Alkaline phosphatase (U/l) & $213 \pm 46$ & $659 \pm 0.300$
\end{tabular}

Data are reported as mean \pm SEM. ${ }^{*}$ All patients had increased rates of bone formation and mild, moderate or severe amounts of marrow fibrosis. PTH = parathyroid hormone.

Table 2. Bone localization of immunoreactive cytokines in patients with osteitis fibrosa.

\begin{tabular}{lccccc}
\hline Cytokines & \multicolumn{2}{c}{ Marrow stroma } & & Osteoblasts & Osteocytes \\
\cline { 2 - 4 } & Fibrotic & Non-fibrotic & & \\
\hline IL-1 $\alpha$ & +++ & 0 & 0 & 0 \\
IL-6 & +++ & 0 & ++ & 0 \\
IL-11 & + & 0 & 0 & 0 \\
TNF- $\alpha$ & +++ & 0 & 0 & ++ \\
TGF- $\beta$ & +++ & 0 & +++ & + \\
\hline
\end{tabular}

$(+)$ weak, $(++)$ moderate or $(+++)$ intense immunostaining.

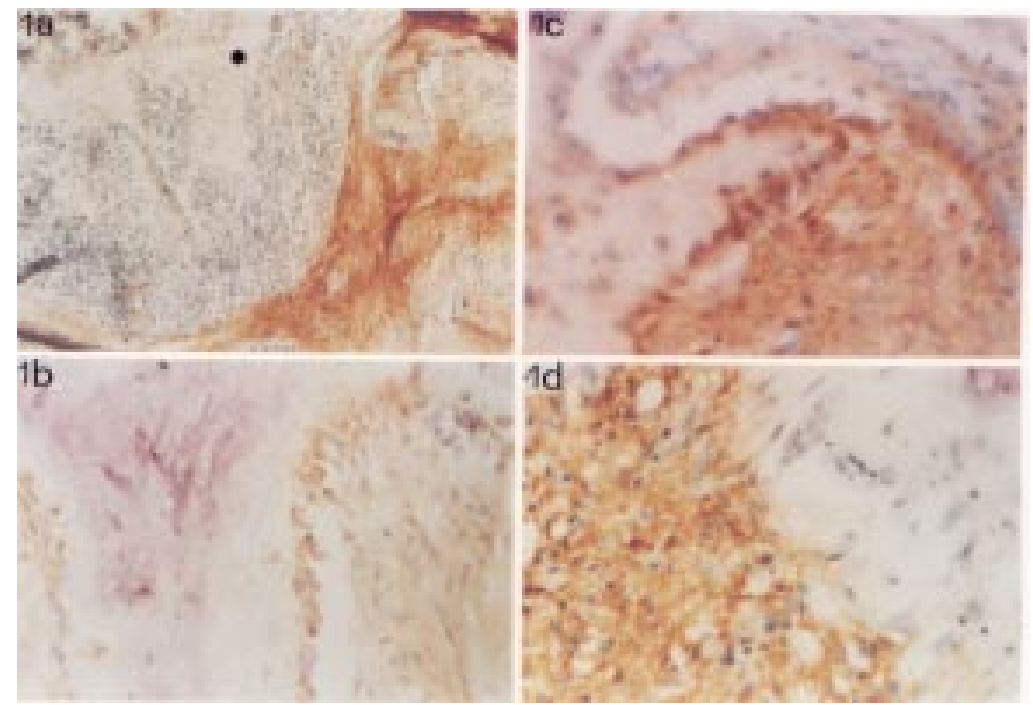

Figure 1. Immunohistochemical localization of cytokines in marrow stroma and in bone cells in osteitis fibrosa. a, Distinct IL-1 $\alpha$ accumulation in marrow fibrous tissue. Note sharp transition zone between heavily positive fibrous marrow stroma and the negative stain for IL-1 $\alpha$ in non-fibrous marrow. Mineralized bone (asterisk) and unmineralized osteoid matrix are negatively stained. b, c, Active, plump osteoblasts immediately adjacent to the osteoid seam expressing immunopositivity for IL-6 (b) and TGF-ß (c). d, High magnification of the transition zone between heavily positive fibrous marrow stroma and the negative stain for TNF- $\alpha$ of bone cells and non-fibrous marrow. Magnification 4X (a) and 40X (b-d). 
immunostaining steps resulted in negative immunostaining of the fibrous marrow. Also, the application of nonimmune sera from animals which produced the same type of secondary antibody failed to stain the bone marrow fibrous stroma or cellular elements.

\section{Discussion}

We have shown that the bone marrow space of patients with secondary hyperparathyroidism shows significant accumulations of IL- $1 \alpha$, IL- 6 , TNF- $\alpha$ and TGF- $\beta$ within discrete areas of fibrosis. The protein staining was usually homogeneous for each cytokine, though occasionally there were areas of fibrosis with apparently higher concentrations of one or more cytokines. Except for IL-11, all of the cytokines tested were relatively equal in their expression at the protein level and, in general, the greater the fibrosis the more intense was the cytokine staining. Thus, patients with the highest circulating PTH levels had the largest amount of fibrosis and the most marrow space that was positive for cytokine accumulation.

We did not attempt to determine which cell type was responsible for cytokine production. As such, any of the marrow stromal elements could be responsible since macrophages, fibroblasts, megakaryocytes and endothelial cells are all capable of secreting one or more cytokines (16). Regardless of the cell type responsible, it is clear that much of the immunoreactivity is localized to the extracellular matrix of the fibrotic areas, suggesting that these cytokines are able to bind certain extracellular matrix proteins. Thus, cytokine accumulation may represent a "feed forward" phenomenon where cells are stimulated to produce cytokines that stimulate cellular proliferation and matrix proteins which then bind and retain the bioactive cytokines. Alternatively, the elevated circulating levels of IL-6, IL- $1 \alpha$ and TNF- $\alpha$, which are present in dialysis patients $(10,11)$ may result in a "trapping" phenomenon within the marrow fibrosis that leads to their accumulation. Because of the descriptive nature of our observation we cannot determine whether there is a causal relationship between cytokine expression and fibrotic response.

One major difference in cytokine expression was noted with respect to cellular localization within bone. Cytoplasmic staining within osteoblasts lining the bone surface was clearly positive for IL- 6 and TGF- $\beta$ but not for the others. This response was more apparent in those patients whose serum PTH levels were the highest, suggesting that $\mathrm{PTH}$ may have had a stimulatory role. Consistent with this notion are several in vitro studies showing that PTH stimulates IL-6 $(13,17)$ and TGF- $\beta$ (18) synthesis in cultured osteoblasts. Interestingly, osteocytes within the mineralized matrix stained positive for TGF$\beta$ only. This is the first report that demonstrates osteocyte immunoreactivity to TGF$\beta$ and suggests that this cytokine may have a role in mediating the osteocytic regulation of osteoblast and osteoclast activity (19).

Our observations suggest that the known stimulatory effect of PTH on osteoblast activity and bone turnover in renal osteodystrophy (3) may be mediated, in part, by its effect in stimulating TGF- $\beta$ and/or IL-6 production. Since osteoblasts produce and bind TGF- $\beta$ and IL-6 $(20,21)$, both are likely to participate in the autocrine/paracrine control of bone remodeling. TGF- $\beta$ stimulates several extracellular matrix proteins, such as fibronectin, type I collagen, and osteopontin, which are required for normal bone mineralization. IL-6, in contrast, acts primarily on the osteoclast by an effect that promotes its differentiation and enhance bone resorption (22). In addition to the stimulatory effect of PTH, TNF- $\alpha$ (21) and IL- $1 \alpha$ (23) also stimulate osteoblast production of IL-6. Thus, while a complex interplay between each cytokine is likely to occur as they potentially modulate bone remodeling in this setting, the overall expected response to excess cy- 
tokine accumulation would be increased bone turnover.

We have shown that the high turnover bone lesion of uremic hyperparathyroidism is characterized by abnormal cytokine accumulation within marrow fibrosis. Our finding that TGF- $\beta$ and IL- 6 are prominent within cells of the osteoblast lineage suggests that they may have a direct role in stimulating bone turnover. The results of this study also provide insight into the utilization of immunohistochemical staining of plastic embedded bone sections as a way to investigate mechanisms of bone remodeling in normal and pathologic conditions.

\section{References}

1. Hasselbach H (1990). Idiopathic myelofibrosis: A review. European J ournal of Haematology, 45: 65-92.

2. Reilly JT (1992). Pathogenesis of idiopathic myelofibrosis: Role of growth factors. J ournal of Clinical Pathology, 45: 461464.

3. Andress DL \& Sherrard DJ (1997). Renal osteodystrophy of chronic renal failure. In: Schrier RW \& Gottschalk CW (Editors), Diseases of the Kidney. Little Brown \& Company, Boston, MA, USA.

4. Hruska KA \& Teitelbaum SL (1995). Renal osteodystrophy. New England J ournal of Medicine, 333: 166-174.

5. J ohnston J B, Dalal BI, Israels SJ, Oh S, McMillan E, Begleiter A, Michaud G, Israels LG \& Greenberg AH (1995). Deposition of transforming growth factor $B$ in the marrow in myelofibrosis, and the intracellular localization and secretion of TGF- $\beta$ by leukemic cells. American J ournal of Clinical Pathology, 103: 574-582.

6. Lisse I, Hasselbach H \& J unker P (1991). Bone marrow stroma in idiopathic myelofibrosis and other haematological diseases. An immunohistochemical study. Acta Pathologica, Microbiologica et Immunologica Scandinavica, 99: 171-178.

7. Martyré $M C$, Madelenat $H$, Bryckaert $M C$, Laine-Bidron C \& Calvo F (1991). Increased intraplatelet levels of platelet-derived growth factor and transforming growth factor- $\beta$ in patients with myelofibrosis with myeloid metaplasia. British J ournal of Haematology, 77: 80-86.

8. Manolagas SC (1998). The role of IL-6 type cytokines and their receptors in bone. Annals of the New York Academy of Sciences, 840: 194-204.
9. Canalis E, McCarthy TL \& Centrella M (1991). Growth factors and cytokines in bone cell metabolism. Annual Review of Medicine, 42: 17-24.

10. Herbelin A, Urena $P$, Nguyen AT, Zingraff J \& Descamps-Latscha B (1991). Elevated circulating levels of interleukin-6 in patients with chronic renal failure. Kidney International, 39: 954-960.

11. Herbelin A, Nguyen AT, Zingraff J , Urena P \& Descamps-Latscha B (1990). Influence of uremia and hemodialysis on circulating interleukin-1 and tumor necrosis factor $\alpha$. Kidney International, 37: 116125.

12. Yoneda T (1993). Cytokines in bone: local translators in cell-to-cell communications. In: Noda M (Editor), Cellular and Molecular Biology of Bone. Academic Press, San Diego, CA, USA

13. Greenfield EM, Shaw SM, Gornic SA \& Banks MA (1995). Adenyl cyclase and interleukin 6 are downstream effectors of parathyroid hormone resulting in stimulation of bone resorption. J ournal of Clinical Investigation, 96: 1238-1244.

14. Villanueva AR \& Mehr LA (1977). Modifications of the Goldner and Gomori-onestep trichrome stain for plastic embedded thin sections of bone. American J ournal of Medical Technology, 43: 536-538.

15. Lucena SB, Duarte MEL \& Fonseca EC (1997). Plastic embedded undercalcified bone biopsies: an immunohistochemical method for routine study of bone marrow extracellular matrix. J ournal of Histotechnology, 20: 253-257.

16. Groopman J E, Molina J M \& Scadden DT (1989). Hematopoietic growth factors. Biology and clinical applications. New Eng- land J oumal of Medicine, 321: 1449-1459.

17. Feyen JHM, Elford P, Di Padova FE \& Trechsel U (1989). Interleukin-6 is produced by bone and modulated by parathyroid hormone. J ournal of Bone and Mineral Research, 4: 633-638.

18. Oursler MJ , Cortese C, Keeting P, Anderson MA, Bonde SK, Riggs BL \& Spelsberg TC (1991). Modulation of transforming growth factor-ßs production in normal human osteoblast-like cells by 17 ß-estradiol and parathyroid hormone. Endocrinology, 129: 3313-3320.

19. Nijweide PJ , Burger EH, Nulend J K \& Van der Plas A (1996). The osteocyte. In: Bilezikian J P, Raisz LG \& Rodan GA (Editors), Principles of Bone Biology. Academic Press, Boston, MA, USA.

20. Centrella M, Horowitz MC, Wozney J M \& McCarthy TL (1994). Transforming growth factor- $\$$ gene family members and bone. Endocrine Reviews, 15: 27-39.

21. Littlewood AJ, Russel J, Harvey GR, Hughes DE, Russell RGGG \& Gowen M (1991). The modulation of the expression of IL- 6 and its receptor in human osteoblasts in vitro. Endocrinology, 129: 15131520.

22. Manolagas SC \& J ilka RL (1995). Bone marrow, cytokines, and bone remodeling. Emerging insights into the pathophysiology of osteoporosis. New England J ournal of Medicine, 332: 305-311.

23. Lacey DL, Grosso LE \& M oser SA (1993). IL-1-induced murine osteoblast IL-6 production is mediated by the type $1 \mathrm{IL}-1$ receptor and is increased by 1,25 dihydroxyvitamin D. J ournal of Clinical Investigation, 91: 1731-1742. 